\title{
Influence of oral administration of HMB to pregnant dams on calbindin expression in the dentate gyrus of the hippocampus during postnatal development in spiny mice offspring
}

\author{
KAROL RYCERZ, ALEKSANDRA KRAWCZYK, JADWIGA JAWORSKA-ADAMU, \\ RADOSŁAW SZALAK, EWA TOMASZEWSKA*, PIOTR DOBROWOLSKI**
}

\begin{abstract}
Department of Animal Anatomy and Histology, *Department of Animal Physiology, Faculty of Veterinary Medicine, University of Life Sciences, Akademicka 12, 20-033 Lublin, Poland

**Department of Comparative Anatomy and Anthropology, Maria Curie-Skłodowska University,
\end{abstract} Akademicka 19, 20-033 Lublin, Poland

Rycerz K., Krawczyk A., Jaworska-Adamu J., Szalak R., Tomaszewska E., Dobrowolski P.

Influence of oral administration of HMB to pregnant dams on calbindin expression in the dentate gyrus of the hippocampus during postnatal development in spiny mice offspring

\section{Summary}

The aim of the study was to investigate the morphology, density and immunostaining intensity of calbindin (CB)-positive neurons of dentate gyrus (DG) in new-born (P0) and 21-day-old (P21) male Acomys cahirinus mice from dams receiving $\beta$-hydroxy- $\beta$-methylbutyrate $(\mathrm{HMB})$ during pregnancy. Different substances administrated to pregnant dams may affect the calcium ion homeostasis which is crucial for the proper brain development of their offspring. DG with hilus $(\mathrm{H})$ plays an important role in memory and learning processes. Calcium levels in DG are regulated by buffering proteins like calbindin D28k (CB). Experimental dams were orally treated with HMB at a dose of $0.2 \mathrm{~g} / \mathrm{kg} \mathrm{b}$.w. Half of new-born animals were euthanised after birth and the rest after the $21^{\text {st }}$ day of life. The brains were dissected and embedded in paraffin blocks using a routine histological technique. In order to demonstrate $\mathbf{C B}$ protein expression an immunohistochemical peroxidase-antiperoxidase reaction was conducted. The results of the study did not reveal important morphological alterations. There were no statistically significant changes in the density of the studied cells either in P0 and P21 animals. However, the authors have demonstrated a statistically significant increase of the average CB-immunostaining intensity in nuclei and cytoplasm in both age groups. It may be a result of a compensation effect to alterations that occurred under the influence of HMB. On the basis of the conducted research, it may be assumed that HMB activity in DG may provide long-term consequences.

Keywords: $\beta$-hydroxy- $\beta$-methylbutyrate, calbindin, dentate gyrus, Acomys cahirinus

The dentate gyrus (DG) with hilus (H) plays an important role in the processes of memory and learning and it is responsible for spatial navigation. A neurogenesis takes place in this area in adult individuals (1, $9,10)$. In the DG of different species of animals the layers: stratum moleculare (SM), stratum granulosum (SG) and hilus $(\mathrm{H})$ were distinguished $(8,18)$. A proper functioning of the area depends largely on the concentration of calcium ions in neurons. They participate in the development of the nervous system by affecting cell divisions, synaptogenesis and neuronal net formation. In neurons they are responsible for synthesis, axonal transport and a release of neurotransmitters $(3,4$, 23). Neuronal calcium levels are strictly regulated by calcium-binding proteins. These include the calbindin-D28k (CB), a buffering and sensory protein $(13,21)$.

$\mathrm{CB}$ in the DG of adult animals is present mainly in granular cells localised near SM. These cells are the excitatory glutamatergic neurons constituting $90 \%$ of all neurons of this area. Moreover, CB is localised in a small number of interneurons in $\mathrm{SM}$ and $\mathrm{SG}$, in basket cells under or in $\mathrm{SG}$ and in $\mathrm{H}(21,24,25)$. The protein stimulates granular cells-mossy fibres system increasing a release of neurotransmitters in the nerve endings 
of hippocampal CA3 region (7,31). A presence of only single CB-immunopositive cells was demonstrated in the DG of mice on the first day of life, which is related with a postnatal development of granular cells (32). However, in the studied species Acomys cahirinus an early development of DG occurs. This area of the brain forms a characteristic shape on the $28^{\text {th }}$ embryonal day. A postnatal hippocampal development in this species is rapid (5).

Different substances may affect the homeostasis of calcium ions in DG neurons, which may alter the activity of the area $(20,31)$. Pregnant dams nutrition can also affect the size of the brain, the number of neurons, behaviour, learning and memory processes of their offspring (16).

$\beta$-hydroxy- $\beta$-methylbutyrate (HMB) is a leucine metabolite used as a diet supplement in order to improve the efficacy of exercises and to gain skeleton muscle hypertrophy $(29,30)$. It has been demonstrated that prenatal administration of HMB has a positive impact on the growth and development of farm animals (26, 27). Until now there were no analyses concerning the influence of a prenatal administration of the HMB to pregnant dams on the morphology and functioning of the brains of their offspring.

The aim of the study was to assess the morphology of CB-positive DG neurons in new-born and 21-day-old male spiny mice (Acomys cahirinus) from dams receiving HMB during pregnancy. An average density and an average immunostaining intensity were analysed in granular neurons of the DG in the studied animals.

\section{Material and methods}

Animals and preliminary examination procedures. The experiment was approved by the First Local Ethical Committee in Lublin, Poland (8/2014). Twelve mice dams which were divided into 2 equal groups (experimental and control) were used for the study. Mice were kept in constant conditions $\left(22^{\circ} \mathrm{C}, 55-60 \%\right.$ humidity, $12 / 12$ day-night cycle). All the animals were fed with standard fodder (LSM, Agropol S.J., Motycz, Poland) with constant access to fresh water. Experimental dams $(n=6)$ were orally treated with $\beta$-hydroxy- $\beta$-methylbutyrate (HMB, Sigma-Aldrich, St. Louis, Missouri, USA) at a dose of $0.2 \mathrm{~g} / \mathrm{kg} \mathrm{b}$.w./day from the $26^{\text {th }}$ day of gestation to birth (approx. the $39^{\text {th }}$ day). The number of new-born animals was 2-4 and did not differ between the groups of animals. Half of new-born males (P0) from the control group $(\mathrm{n}=6)$ and experimental group $(\mathrm{n}=7)$ were euthanised by $\mathrm{CO}_{2}$ inhalation. Other mice, control $(n=6)$ and experimental $(n=7)$, were euthanised on the $21^{\text {st }}$ day of life (P21). Immediately after death the brains were dissected. The material was fixed in $10 \%$ buffered formalin $(\mathrm{pH}=7.0)$ for $12 \mathrm{~h}$ at $4^{\circ} \mathrm{C}$ and embedded in paraffin blocks. The blocks containing hippocampus were cut in microtome (A $4230 \mu \mathrm{m}$-A $3750 \mu \mathrm{m}$, according to the atlas by König and Klippel) (14). Frontal, $6 \mu \mathrm{m}$-thick slices were put on the slides, deparaffinised in xylene and hydrated in a graded series of alcohol.
Immunohistochemistry. In order to demonstrate $\mathrm{CP}$ protein expression, indirect immunohistochemical peroxidase-antiperoxidase (PAP) reaction was performed. Slices were treated with $0.4 \% \mathrm{H}_{2} \mathrm{O}_{2}$ (30 min., room temperature) to inhibit the activity of endogenous peroxidase. Background staining was removed by incubation in normal goat serum (20 min., room temperature). Subsequently, a primary specific monoclonal mouse anti- $\mathrm{CB}$ antibody and the monoclonal goat anti-IgG-peroxidase secondary antibody (both from Sigma-Aldrich, St. Louis, Missouri, USA) were used. 3,3'-diaminobenzidine tetrahydrochloride (DAB, Sigma-Aldrich) was used as a chromogen. The slices were consecutively rinsed in distilled $\mathrm{H}_{2} \mathrm{O}$, counterstained with Mayer's haematoxylin, dehydrated, cleared in xylene and mounted in DPX (Fluka, Buchs, Switzerland). A specificity control was conducted. CB-immunopositive neurons of hippocampal DG were analysed and photographed in Olympus BX51 light microscope (Olympus, Tokyo, Japan) with digital camera (Olympus Color View III). CB immunostaining intensity for morphological assessment was rated as weak $(+)$, moderate $(++)$ and intensive $(+++)$.

Morphometric analyses. The SG layer was evaluated morphometrically. A sparse expression of CB in SM and $\mathrm{H}$ did not provide adequate material for quantitative analysis and was not considered further. An average density of CB-positive cells in $2.5 \times 10^{-3} \mathrm{~mm}^{2}$ and an average digital immunostaining intensity were assessed. 50 slides were randomly chosen from every group (a similar number of slides from each animal). 2 microphotographs of DG with $\mathrm{H}$ were taken from every slide and were analysed in Cell $^{\wedge} \mathrm{D}$ program (Olympus, Tokyo, Japan). A grid of squares $\left(2.5 \times 10^{-3} \mathrm{~mm}^{2}\right)$ was imposed on the microphotographs in a way that the test area covered the SG layer entirely in P0 and P21 animals. In P21 animals, in both groups, only the squares from $\mathrm{SG}$ which were adjacent to $\mathrm{SM}$ were selected to count. CB-positive cells were counted manually in randomly chosen microphotographs to obtain a measurement of the 100 squares from SG. On the basis of the results an average density of CB-positive cells in $2.5 \times 10^{-3} \mathrm{~mm}^{2}$ was defined and experimental groups (P0 and P21) were compared with control groups. Moreover, 100 measurements of digital immunostaining intensity were collected from the granular cells nuclei and cytoplasm. The results were converted, standardised and presented as an average digital immunostaining intensity in the optical units $/ \mu \mathrm{m}^{2}\left(\mathrm{ou} / \mu \mathrm{m}^{2}\right)$.

Statistical analyses. The results of the average cell density did not show a normal distribution and were compared between the control group and the experimental animals (P0 and P21) using the non-parametric Kruskal-Wallis test $(\alpha=0.05)$. Differences in digital immunostaining intensity were analysed by the ANOVA test with the Tukey HSD $(\alpha=0.05)$. Analyses were carried out in the R 3.0.2 program (Free Software Foundation's GNU General Public License, http://www.r-project.org/).

\section{Results and discussion}

Morphology of CB-immunoreactive neurons. CB-immunopositive cells were present in all layers of DG and $\mathrm{H}$ in control and experimental animals. In the SM layer of P0 control animals only single, brown 


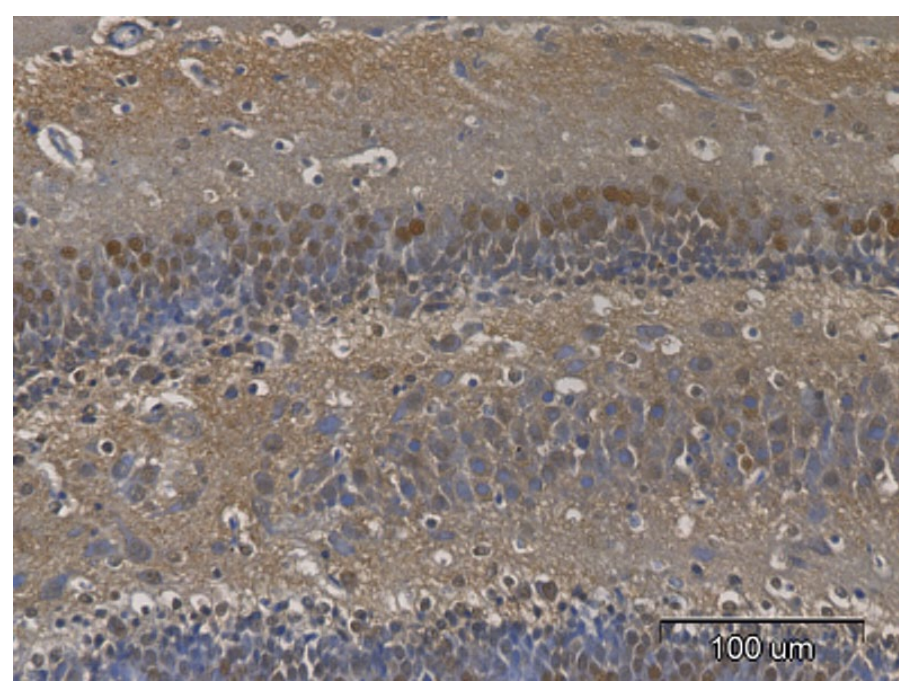

Fig. 1. CB-immunopositive neurons in the dentate gyrus of a control new-born mouse

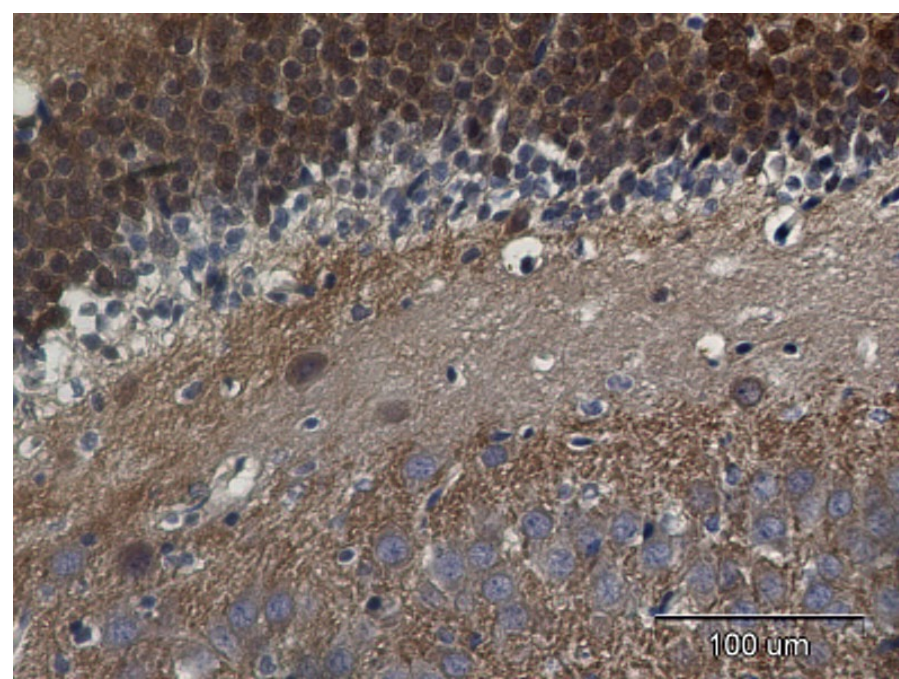

Fig. 3. CB-immunopositive neurons in the dentate gyrus of a 21-day-old control mouse

and round cells with weak $(+)$ immunostaining were demonstrated. Numerous, intensively $(+++)$ and moderately $(++)$ stained round granular cells, characterised mainly by nuclear CB-reactivity, were present in SG. They were localised directly under the SM layer. Single, oval and fusiform neurons with moderate $(++)$ and weak $(+)$ reaction in nucleus and cytoplasm were observed in $\mathrm{H}$ (Fig. 1).

In P0 experimental animals, CB-positive cells in the SM layer were round and characterised by moderate $(++)$ nuclear reaction. Numerous, round granular cells with nuclear and nucleocytoplasmic reaction were demonstrated in SG. Intensively stained $(+++)$ cells were localised under the SM layer. Oval and a few fusiform cells with moderate intensity of the staining $(++)$ were present in $\mathrm{H}$ as in the control animals (Fig. 2).

In the dentate gyrus of P21 control animals single, oval and round neurons with intensively immunostained $(+++)$ nuclei were observed in SM. Numerous granular

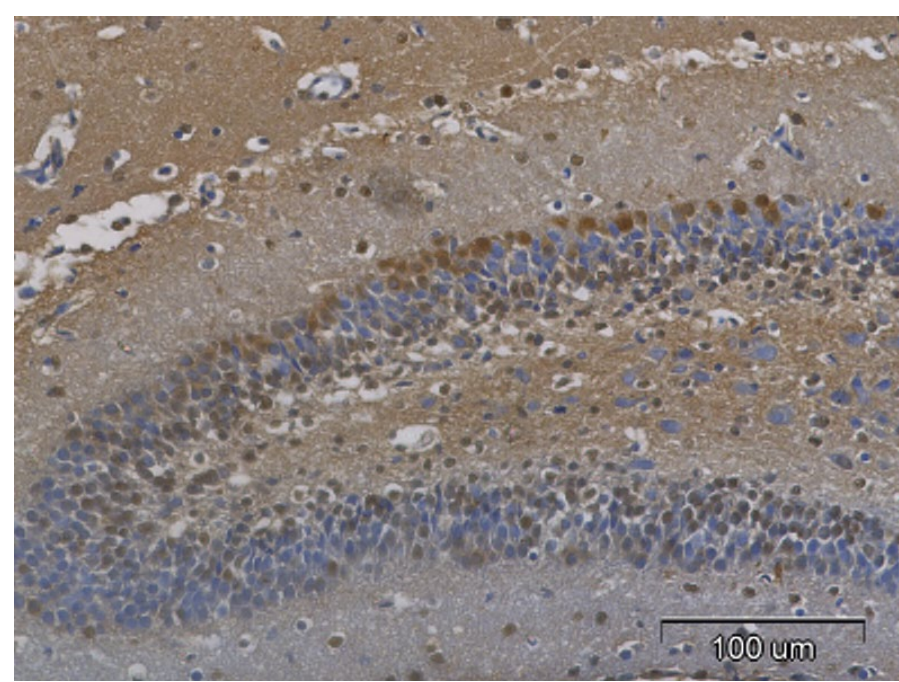

Fig. 2. CB-immunopositive neurons in the dentate gyrus of a new-born mouse from a dam treated with HMB during pregnancy

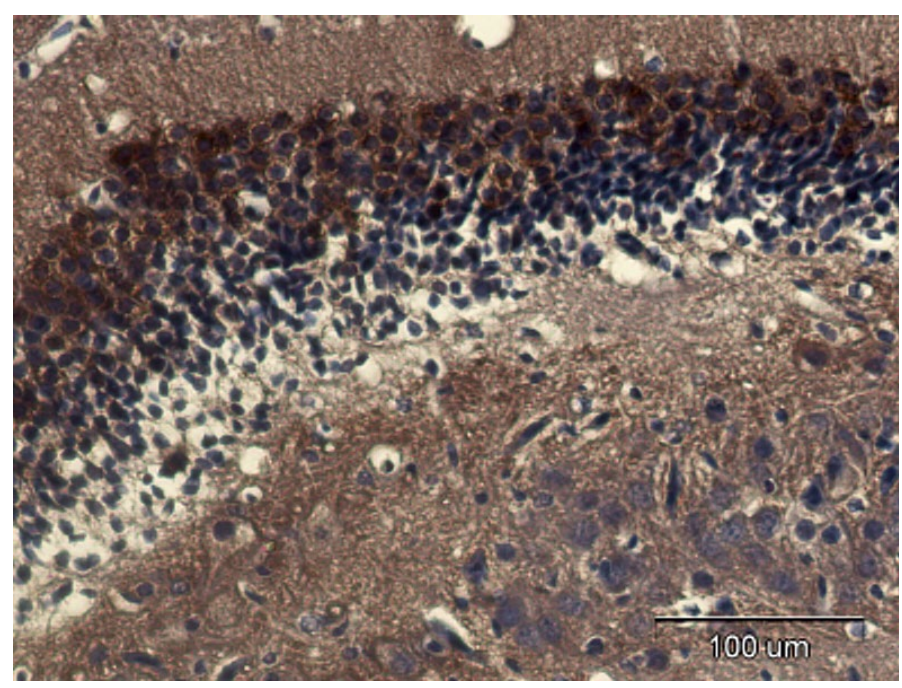

Fig. 4. CB-immunopositive neurons in the dentate gyrus of a 21-day-old mouse from a dam treated with HMB during pregnancy

cells $(+++)$ were localised in SG directly under SM. The cells near $\mathrm{H}$ did not show $\mathrm{CB}$-immunoreactivity. Mainly fusiform and oval neurons with cytoplasmic and moderate $(++) \mathrm{CB}$ expression were demonstrated in $\mathrm{H}$ (Fig. 3.).

In P21 experimental animals as in control individuals single, oval and round cells with intensive immunostaining $(+++)$ were localised in SM of the dentate gyrus. Round granular cells from SG layer of the experimental animals were intensively immunostained $(+++)$ but there was an advantage of neurons with cytoplasmic reaction and they were localised under SM. As in the control group, the cells observed near $\mathrm{H}$ were CB-negative. A few, fusiform and oval neurons with moderate $(++)$ and rarely intensive $(+++)$ reaction were demonstrated in $\mathrm{H}$ (Fig. 4).

Morphometric analyses of CB-immunoreactive neurons. The assessment of the average density of cells/ $2.5 \times 10^{-3} \mathrm{~mm}^{2}$ in SG of the dentate gyrus in $\mathrm{P} 0$ animals 
revealed no statistically significant differences between the studied groups, i.e. the control and experimental group. In P21 as in new-born animals, there were also no statistically significant differences in the density of granular neurons between the offspring from mothers receiving the HMB and the control group (Fig. 5).

The studies of the digital immunostaining intensity revealed a statistically significant increase in the staining intensity of nuclei and cytoplasm of SG layer cells in P0 animals from the HMB group in comparison with the control group (ANOVA $p<0.05$ ). Similarly, a statistically significant increase of the digital immunostaining intensity of granular cells nuclei and cytoplasm was observed in P21 animals (ANOVA $\mathrm{p}<0.05$ ) (Fig. 6).

Our studies have demonstrated that orally administrated HMB to pregnant Acomys cahirinus dams from the $26^{\text {th }}$ day of pregnancy until birth at a dose of $0.2 \mathrm{~g} / \mathrm{kg}$ b.w./day does not result in significant alterations in the morphology of CB-positive neurons of hippocampal dentate gyrus in new-born and 21-day-old male mice in comparison with control individuals. There were no statistically significant changes in the density of the studied cells in SG of hippocampal dentate gyrus between control and experimental group, both in P0 and P21 animals.

However, the study demonstrates a statistically significant increase of the average CB-immunostaining intensity both in nuclei and cytoplasm of SG layer neurons in both age groups. Although the DAB staining does not follow the Lambert-Beer law, our own analyses revealed a constant, statistically significant increase of CB-positive cells staining intensity. The measurements suggest a growing trend of the protein reactivity in offspring from dams treated with HMB. Moreover, it was demonstrated that the content of different antigens in cells may correlate with the DAB immunostaining intensity $(15,22,28)$. In this case, the increase of immunostaining may indicate a change in the $\mathrm{CB}$ protein activity and $\mathrm{Ca}^{2+}$ homeostasis in granular cells. It was shown that the increase of CB expression in these neurons causes an increased transduction of mossy fibres (MF) and an increased release of neurotransmitters in MF-CA3 synapses. Furthermore, CB overexpression inhibits a paired pulse facilitation (PPF) and a long term potentiation (LTP) leading to spatial memory impairment. Studies suggest that functioning of the hippocampus may be disrupted by excessive binding of calcium ions. The adjust of single calcium binding protein concentration alters a synaptic functioning of a distinct population of neurons (7). Every change in the levels of calcium ions may alter seizure activity of neuronal cells (31). A high level of intracellular calcium may be a one of the main reasons of neurodegeneration related to excitotoxicity (2). An increase of the immunostaining in CB-positive cells in offspring treated with $\mathrm{HMB}$ via the placenta from its dam may

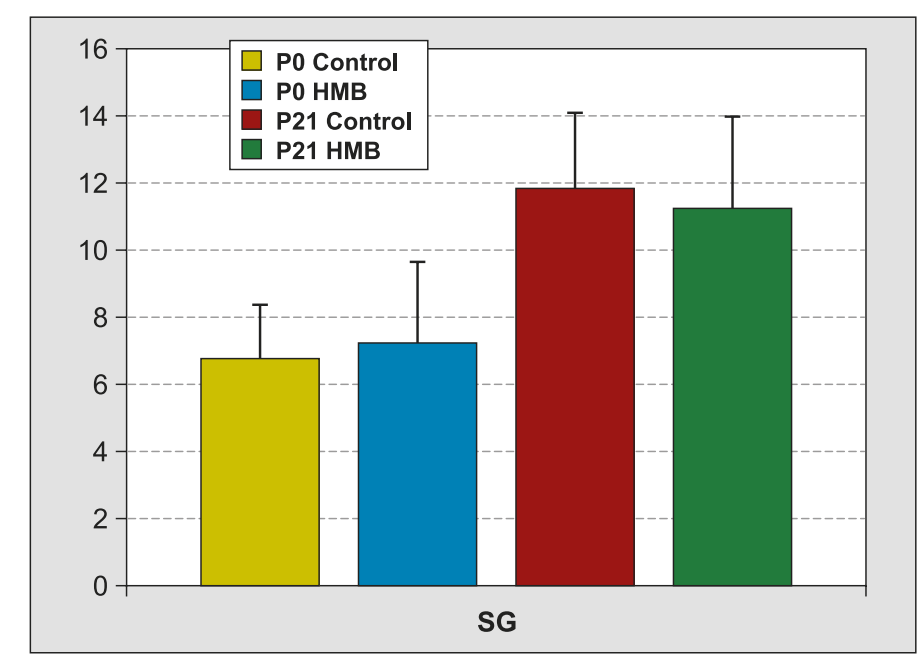

Fig. 5. The density of CB-immunopositive cells in the granular layer of the dentate gyrus in the control and experimental (HMB) new-born (P0) and 21-day-old (P21) mice. Data shows mean density of CB-immunopositive cells in the area of $2.5 \times 10^{-3} \mathrm{~mm}^{2}$ with standard deviation bars

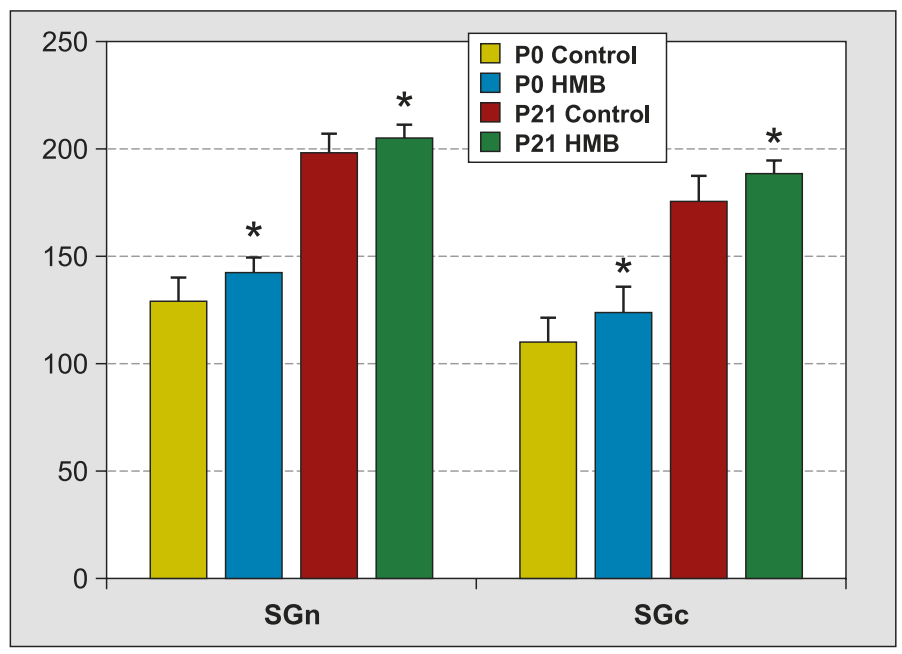

Fig. 6. The average digital immunostaining intensity of $\mathrm{CB}$ -positive cells in the granular layer of the dentate gyrus in the control and experimental (HMB) new-born P0 and 21-day-old (P21) mice. Data shows mean staining intensity with standard deviation bars in granular cells nuclei (SGn) and cytoplasm (SGc) expressed in $\mathrm{ou} / \boldsymbol{\mu m}^{2}$.

Explanation: *statistically significant differences between control and HMB groups (ANOVA, $\mathrm{p}<0.05$ )

be a compensatory mechanism against the increased intracellular levels of calcium ions. CB buffers the calcium potentials in neurons (21). Studies proved that an increase of CB levels protects neurons against glutamate excitotoxic activity. This neurotransmitter causes energetic disruptions in cells leading to alterations of calcium concentration regulation. The presence of $\mathrm{CB}$ in neurons prevents changes in the levels of ATP (20). Varied CB expression in neurons of the hippocampus may determine the sensitivity of cells to excitotoxic disorders. This is due to a possibility of intracellular free calcium levels modulation. Moreover, other authors' studies revealed that neurons with a CB expression are more resistant to high calcium levels 
$(6,19)$. This phenomenon is crucial for granular cells development which takes places in a specific range of intracellular $\mathrm{Ca}^{2+}$ concentrations. The studied protein may potentially contribute to the maintenance of a necessary $\mathrm{CA}^{2+}$ concentration for neuronal growth (17). In addition, $\mathrm{CB}$ expression in granular neurons correlate with functional development of the dentate gyrus and behavioural maturation of rats. The protein plays an important role in LTP and synaptic consolidation in hippocampal memory processes (11). We have demonstrated that in animals from dams receiving $\mathrm{HMB}$ there is an increase of CB immunostaining. In young animals an increased concentration of the protein in nervous cells may affect their differentiation during development. CB leads to up-regulation of NeuroD, Mash1 and Pax6 genes inducing a neuronal development. CB-transfected neurons were characterised by longer processes (12).

To sum up, a slight but statistically significant increase of CB immunostaining intensity in the DG and $\mathrm{H}$ of $\mathrm{P} 0$ and $\mathrm{P} 21$ mice demonstrated in our study may not reflect an impairment of $\mathrm{Ca}^{2+}$ homeostasis. It may be a result of a compensation effect to alterations that occurred under the influence of HMB. We have shown that HMB administrated to Acomys cahirinus dams during pregnancy passes the placental barrier, enters the brain and affects a distinct populations of the DG cells. We suggest that its activity in the brain may provide long-term consequences. Thus, further studies which will shed light on the mechanisms of HMB action in the central nervous system are necessary.

\section{References}

1.Abraham H., Veszpremi B., Kravjak A., Kovács K., Gömöri E., Seress L.: Ontogeny of calbindin immunoreactivity in the human hippocampal formation with a special emphasis on granule cells of the dentate gyrus. Int. J. Devl. Neurosci. 2009, 27, 115-127.

2. Arundine M., Tymianski M.: Molecular mechanisms of calcium-dependent neurodegeneration in excitotoxicity. Cell Calcium 2003, 34, 325-337.

3. Bootman M. D., Collins T. J., Peppiatt C. M., Prothero L. S., MacKenzie L., De Smet P., Travers M., Tovey S. C., Seo J. T., Berridge M. J., Ciccolini F. Lipp P.: Calcium signalling - an overview. Semin. Cell Dev. Biol. 2001, 12, 3-10.

4. Bregestovski P., Spitzer N.: Calcium in the function of the nervous system New implications. Cell Calcium 2005, 37, 371-374

5. Brunjes P. C.: The precocial mouse, Acomys cahirinus. Physiology 1990, 18, 339-350

6. D'Orlando C., Celio M. R., Schwaller B.: Calretinin and calbindin D-28k, but not parvalbumin protect against glutamate-induced delayed excitotoxicity in transfected N18-RE 105 neuroblastoma-retina hybrid cells. Brain Res. 2002, 945, 181-190.

7. Dumas T. C., Powers E. C., Tarapore P. E., Sapolsky R. M.: Overexpression of Calbindin d28k in dentate Gyrus Granule Cells Alters Mossy Fiber Presynaptic Function and Impairs Hippocampal-Dependent Memory. Hippocampus 2004, 14, 702-709

8. El Falougy H., Kubikova E., Benuska J.: The microscopical structure of the hippocampus in the rat. Bratisl. Lek. Listy 2008, 109, 106-110.

9. Eriksson P. S., Perfilieva E., Bjork-Eriksson T., Alborn A. M., Nordborg C., Peterson D. A., Gage F. H.: Neurogenesis in the adult human hippocampus. Nat. Med. 1998, 4, 1313-1317.

10. Gage F. H., Kempermann G., Palmer T. D., Peterson D. A., Raj J.: Multipotent progenitor cells in the adult dentate gyrus. J. Neurobiol. 1998, 36, 249-266.
11. Karadi K., Janszky J., Gyimesi C., Horváth Z., Lucza T., Dóczi T., Kállai J., Abrahám H.: Correlation between celbindin expression in granule cells of the resected hippocampal dentate gyrus and verbal memory in temporal lobe epilepsy. Epilepsy Behav. 2012, 25, 110-119.

12. Kim J. H., Lee J., Song Y. M., Park C. H., Hwang S. J., Kim Y. S., Kaang B. K., Son $H .:$ Overexpression of calbindin-D28K in hippocampal progenitor cells increases neuronal differentiation and neurite outgrowth. FASEB J. 2006, 20, 109-111.

13. Kojetin D. J., Venters R. A., Kordys D. R., Thompson R. J., Kumar R., Cavanagh J.: Structure, binding interface and hydrophobic transities of Ca2+-loaded calbindin-D28k. Nat. Struct. Mol. Biol. 2006, 13, 641-647.

14. König J. F. R., Klippel R. A.: The Rat Brain: A stereotactic atlas of the forebrain and lower parts of the brain stem. Williams\&Willkins, Baltimore 1963.

15. Loos C. M. van der: Multiple immunoenzyme staining: Methods and Visualizations for the Observation With Spectral Imaging. J. Histochem. Cytochem. 2008, 56, 313-328.

16. Lucas A.: Programming by Early Nutrition: An Experimental Approach. J. Nutr. 1998, 128, 401S-406S

17. Luiten P. G. M., Buwalda B., Traber J., Nyakas C.: Induction of enhanced postnatal expression of immunoreactive calbindin-D28k in rat forebrain by the calcium antagonist nimodipine. Brain Res. Dev. Brain Res. 1994, 79, 10-18.

18. Łuszczewska-Sierakowska I., Wawrzyniak-Gacek A., Krawczyk-Marć I., Jarosz Ł., Grądzki Z., Tatara M. R.: Morphological and histological analysis of the hippocampal formation in the American mink. Med. Weter. 2014, 70, 428-431

19. Mattson M. P., Rychlik B., Chu C., Christakos S.: Evidence for calcium-reducing and excitoprotective roles for the calbindin-binding protein calbindin-D28k in cultured hippocampal neurons. Neuron 1991, 6, 41-51.

20. Monje M. L., Philips R., Sapolsky R.: Calbindin overexpression buffers hippocampal cultures from the energetic impairments caused by glutamate. Brain Res. 2001, 911, 37-42.

21. Muller A., Kukley M., Stausberg P., Beck H., Müller W., Dietrich D.: Endogenous $\mathrm{Ca} 2+$ buffer concentration and $\mathrm{Ca} 2+$ microdomains in hippocampus neurons. J. Neurosci. 2005, 25, 558-565.

22. Nguyen D. H., Zhou T., Shu J., Mao J. H.: Quantifying chromogen intensity in immunohistochemistry via reciprocal intensity. Cancer InCytes 2013, 2, 1-4.

23. Rausche G., Igelmund P., Heinemann U.: Effects of changes in extracellular potassium, magnesiumand calcium concentration on synaptic transmission in area CA1 and the dentate gyrus of rat hippocampal slices. Pflugers Arch. 1990, 415, 588-593.

24. Seress L.: Comparative anatomy of the hippocampal dentate gyrus in adult and developing rodents, non-human primates and humans. Prog. Brain Res. 2007, 163, 23-41.

25. Sloviter R. S.: Calcium-binding protein (calbindin-D28k) and parvalbumin immunocytochemistry: localisation in the rat hippocampus with specific reference to the selective vulneralibity of hippocampal neurons to seizure activity. J. Comp. Neurol. 1989, 280, 183-196.

26. Tatara M. R.: Neonatal programming of sceletal development in sheep is mediated by somatotrophic axis function. Exp. Physiol. 2008, 93, 763-772.

27. Tatara M. R., Krupski $W$.: Prenatal programming of skeletal development in the offspring: effects of Materna treatment with $\beta$-hydroxy- $\beta$-methylbutyrate (HMB) on femur properties in pigs at slaughter age. Bone 2007, 40, 1615-1622.

28. Watanabe J., Asaka Y., Kanamura S.: Relationship between immunostaining intensity and antygen content in sections. J. Histochem. Cytochem. 1996, 44, 1451-1458.

29. Wilkinson D. J., Hossain T., Hill D. S.: Effect of leucine and its metabolite $\beta$-hydroxy- $\beta$-methylbutyrate on human skeletal muscle protein metabolism. J. Physiol. 2013, 591, 2911-2923.

30. Wilson G. J., Wilson J. M., Mannien A. H.: Effects of beta-hydroxy-betamethylbutyrate (HMB) on exercise performance and body composition across varying levels of age, sex and training experience: A review. Nutr. Metab. 2008, 5, 1-17.

31. Yang Q., Wang S., Hamberger A., Celio M. R., Haglid K. G.: Delayed Decrease of Calbindin Immunoreactivity in the Granule Cell-Mossy Fibers alter Kainic Acid-Induced Seizures. Brain Res. Bull. 1997, 43, 551-559.

32. Yoo D. Y., Yoo K., Park J. H., Ji Won C., Woosuk K., In Koo H., Moo-Ho W. Detailed differentiation of calbindin D-28-k-immunoreactive cells in the dentate gyrus in C57BL/6 mice at early postnatal stages. Lab. Anim. Res. 2011, 27, 153-159.

Corresponding author: Vet. surg. Karol Rycerz, Akademicka 12, 20-033 Lublin, e-mail: karol.rycerz@up.lublin.pl 